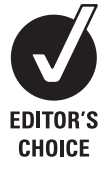

- An additional appendix is published online only at http:// adc.bmj.com/content/vol94/ issue11

${ }^{1}$ Child Health, School of Medicine, Cardiff University, Cardiff, UK; ${ }^{2}$ Department of Primary Care and Public Health, School of Medicine, Cardiff University, Cardiff, UK; ${ }^{3}$ Support Unit for Research Evidence, Cardiff University, Cardiff, UK

Correspondence to:

S Maguire, Child Health, School of Medicine, Cardiff University, Heath Park, Cardiff CF14 4XN, UK; sabinemaguire@yahoo.co. uk

Accepted 12 May 2009 Published Online First 15 June 2009

\title{
Which clinical features distinguish inflicted from non- inflicted brain injury? A systematic review
}

\author{
S Maguire, ${ }^{1}$ N Pickerd, ${ }^{1}$ D Farewell, ${ }^{2}$ M Mann, ${ }^{3}$ V Tempest, ${ }^{1}$ A M Kemp ${ }^{1}$
}

\section{ABSTRACT}

Aim: A systematic review of the scientific literature to define clinical indicators distinguishing inflicted (iBI) from non-inflicted brain injury (niBI).

Methods: An all language literature search of 20 electronic databases, websites, references and bibliographies from 1970-2008 was carried out. Relevant studies were independently reviewed by two trained reviewers, with a third review where required. Inclusion criteria included primary comparative studies of $\mathrm{iBI}$ and niBl in children aged $<18$ years, with high surety of diagnosis describing key clinical features. Multilevel logistic regression analysis was conducted, determining the positive predictive value (PPV) and odds ratios (OR) with $p$ values for retinal haemorrhage, rib/long bone/skull fractures, apnoea, seizures and bruising to head/neck.

Results: 8151 studies were identified, 320 were reviewed and 14 included, representing 1655 children, 779 with iBI. Gender was not a discriminatory feature. In a child with intracranial injury, apnoea (PPV 93\%, OR 17.06, $p<0.001$ ) and retinal haemorrhage (PPV 71\%, OR 3.504, $p=0.03$ ) were the features most predictive of iBI. Rib fractures (PPV 73\%, OR 3.03, $p=0.13$ ) had a similar PPV to retinal haemorrhages, but there were less data for analysis. Seizures and long bone fractures were not discriminatory, and skull fracture and head/neck bruising were more associated with niBI, although not significantly so.

Conclusions: This systematic review shows that apnoea and retinal haemorrhage have a high odds ratio for association with $\mathrm{iBl}$. This review identifies key features that should be recorded in the assessment of children where $\mathrm{iBl}$ is suspected and may help clinicians to define the likelihood of iBI.

In 1974, radiologist John Caffey published his paper "The whiplash shaken infant syndrome: manual shaking by the extremities with whiplash induced intracranial and intraocular bleedings, linked with residual permanent brain damage and mental retardation". ${ }^{1}$ The title captured a proposed mechanism for the most serious form of physical child abuse and referred to the association of intracranial and retinal haemorrhages. The article described the diagnostic challenges of identifying a condition where there are often no external signs of trauma to the head, skull fractures or a history of trauma of any kind, and associated injuries may be subtle or occult, particularly in the case of coexisting fractures. Caffey recognised that these children were often subjected to repeated traumatic episodes. Despite advances in investigative neurology and widespread awareness of this condition, inflicted brain injury (iBI) is commonly

\section{What is already known on this topic}

- Considerable scepticism is being expressed as to how to distinguish inflicted (iBI) from noninflicted brain injury (niBI).

- Varying weight has been given to specific clinical features of $\mathrm{BBI}$ in previous publications.

- Apnoea, retinal haemorrhages and rib fractures are felt to be important but there is no comprehensive statistical estimate of predictive power regarding $\mathrm{iB}$.

\section{What this study adds}

- The finding of apnoea and/or retinal haemorrhage in a child with a brain injury is more strongly associated with $\mathrm{iBI}$ than niBI.

- Children where iBI may be a differential diagnosis should undergo fundoscopy by an ophthalmologist and if $<2$ years old should have a skeletal survey.

- Infants less than 6 months of age with a brain injury are more likely to have sustained an iBI than older infants.

under-recognised ${ }^{2}{ }^{3}$ and remains a diagnostic challenge.

Children with iBI often present with significant intracranial injury in the context of a history of a minor fall, trivial injury or no reported trauma. Clinical symptoms and signs vary from the most non-specific, for example vomiting or irritability, to those that clearly point to a central neurological insult such as reduced consciousness. ${ }^{4}$ Some may present with other inflicted injuries, such as bruising or fractures, as the primary indicator. For some children with a non-specific clinical presentation, the possibility of an iBI may not be considered. $^{35}$ As in most cases of physical child abuse there is no diagnostic test for iBI, the diagnosis is made on a balance of probability and after careful exclusion of other possible causes of the clinical presentation which include accidental injury and medical conditions such as rare metabolic conditions (glutaric aciduria ${ }^{6}$ ), coagulation disorders, ${ }^{7-9}$ infective encephalopathies, etc. It has been recognised that up to $50 \%$ of children with iBI had presented previously with signs of physical abuse that were missed. ${ }^{23}$

Although well recognised as a condition that is prevalent in infants and babies, the estimated 


\section{Box 1 Databases and websites searched}

\section{Databases}

- All EBM Reviews - ACP Journal Club (ACP), Cochrane Database of Systematic Reviews (COCH), Database of Abstracts of Reviews of Effects (DARE), Cochrane Central Register of Controlled Trials, Health Technology Assessment, National Health Service Economic Evaluation, Cochrane Methodology Register

- ASSIA (Applied Social Sciences Index and Abstracts)

- ChildData

- CINAHL (Cumulative Index to Nursing and Allied Health Literature)

- EMBASE

- MEDLINE

- MEDLINE In-Process \& Other Non-Indexed Citations

- SCOPUS

- Open SIGLE (System for Information on Grey Literature in Europe)

- Social Care Online

- TRIP Plus

- Web of Knowledge - ISI Proceedings

- Web of Knowledge - ISI Science Citation Index

- Web of Knowledge - ISI Social Science Citation Index

Websites

- The Child Brain Injury Trust (CBIT), www.cbituk.org

- Child Welfare Information Gateway (formerly National Clearing House on Child Abuse and Neglect), http://www.childwelfare. gov/

- International Society for Prevention of Child Abuse and Neglect (ISPCAN), http://www.ispcan.org/

- The National Center on Shaken Baby Syndrome, http://www. dontshake.com/

*Up to 2005 when the database ceased indexing.

incidence of inflicted head injury is 21-24 per 100000 infants under the age of 1 year. ${ }^{10}{ }^{11}$ Cases may present regularly to specialist neurology units but present infrequently to general paediatric units. Clinicians in all settings need to be aware of the clinical indicators for this condition to make evidence based decisions as to when they should consider investigating an infant where $\mathrm{BBI}$ is a possible cause and to inform a final diagnosis. Many are asked to present their professional or expert opinion in the family or criminal courts as part of the child protection process and they must be able to cite relevant evidence to back up their statements. Although there is a considerable amount of published scientific literature in this field, there have been few attempts to systematically review and critically appraise the world literature. We have attempted to repair this deficit and have addressed the question: "What are the clinical features that distinguish inflicted from non-inflicted brain injury?". The neuro-radiological features of $\mathrm{BBI} / \mathrm{niBI}$ are the subject of a separate review.

\section{METHODS}

We conducted an all language literature search from 1970-2008, searching 20 databases, websites, references and bibliographies, using over 100 keyword combinations (box 1, table 1). This yielded 320 studies for review by reviewers, drawn from paediatricians, paediatric neurologists, neuro-radiologists and ophthalmologists, designated and named doctors/nurses in child protection. All reviewers underwent standardised critical appraisal training, based on the NHS Centre for Reviews and Dissemination critical appraisal standards, ${ }^{12}$ supported by a dedicated electronic critical appraisal module. All studies underwent two independent reviews and a third if there was disagreement (fig 1).

\section{Inclusion/exclusion criteria and quality standards}

We defined the term "brain injury" as extra-axial haemorrhage (subdural, extradural, subarachnoid) and/or injury to the brain (hypoxic ischaemic injury, parenchymal injury, contusion, diffuse axonal injury, cerebral oedema). Inclusion/exclusion criteria are listed in box 2 . Inflicted brain injury (iBI), the item of interest, refers to children who had sustained brain injury from physical child abuse. Those with non-inflicted brain injury (niBI) had other causative mechanisms including accidental trauma, and medical causes of intracranial lesions.

Given the nature of this research field, our optimal study type was population based studies that compared the clinical features of $\mathrm{iBI}$ and niBI with consecutive case ascertainment. As only studies with both niBI and iBI cases could be used for any analysis of predictive power of the features identified, many oft cited (non-comparative) studies were not eligible for inclusion. The included studies detailed the clinical features of interest but did not rely solely on these for the determination of diagnosis (iBI vs niBI). Only studies after 1970 were considered for inclusion, as radiological techniques prior to this would not be relevant to current practice. Included studies had a high surety of diagnosis of $\mathrm{iBI}^{13}$ and confirmation of cause in niBI. To determine a high surety of abuse, we implemented our previously published "ranking of abuse", that is, children stated as "abused" in the study had had that outcome confirmed by multi-agency child protection teams, legal decision, witnessed

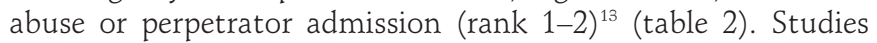
where the decision of abuse had relied solely on clinical features were excluded to minimise selection bias and circularity. Where studies included a category "aetiology indeterminate", these cases were excluded from the final analysis.

\section{Statistical analysis}

The analysis was limited by the items that the authors chose to report and we were able to analyse the following features:

- apnoea

- retinal haemorrhages

- rib fractures

- long bone fractures

- bruising to the head and/or neck

- seizures

- skull fractures.

We were dependent on the primary authors' definitions of the above terms. "Apnoea" reflects either recorded or reported apnoea in the two studies that recorded this item. ${ }^{14} 15$ "Seizures" were not always defined, but some authors did record that some children presented in status epilepticus. " "Long bone fractures" included any fracture to the femur, tibia, fibula, radius, ulna or humerus. Likewise, "skull" or "rib fractures" included any type or location of fracture, respectively.

We included only data from studies where a key feature was explicitly mentioned by the authors. Further, even when a feature was included in the study, not all children in each group were examined for the feature in question. For example, not all children in the niBI group had a fundoscopy examination to look for retinal haemorrhages. We have elected to adopt an 
Table 1 Keywords and search strategy

\begin{tabular}{|c|c|c|}
\hline Keywords & & \\
\hline \multicolumn{3}{|l|}{ Set 1} \\
\hline battered child & child protection & non-accidental injury \\
\hline shaken baby & children & non-accidental trauma \\
\hline battered baby & inflicted brain injury & physical abuse \\
\hline battered infant or shaken infant & inflicted cerebral injury & shaking baby syndrome \\
\hline child & inflicted traumatic head injury & shaking impact syndrome \\
\hline child abuse & inflicted traumatic brain & soft tissue injury \\
\hline child maltreatment & intentional abuse & \\
\hline \multicolumn{3}{|l|}{ Set 2} \\
\hline abusive head trauma & growing skull fracture & intraventricular hematoma \\
\hline bleeding into brain & haematoma & laceration \\
\hline blow to the head & haemorrhagic retinopathy & laminar necrosis \\
\hline brain & head injuries & leptomeningeal cyst \\
\hline brain damage & head trauma & multiple skull fracture \\
\hline brain haemorrhages & hematoma & neurologic injury in child abuse \\
\hline brain hemorrhages & hemorrhagic retinopathy.af. & neuropathology \\
\hline brain injuries & hydrocephalus & non-accidental head injury \\
\hline brain swelling & hygroma & parafalcine \\
\hline brainstem & hypoxic-ischaemic injury & parenchymal contusion, laceration \\
\hline central nervous system & hypoxic-ischemic injury & retinal haemorrhage \\
\hline cerebral & impact injury & retinal hemorrhage \\
\hline cerebral atrophy & infarction & sciwora \\
\hline cerebral edema & inflicted brain injury & shaking impact syndrome \\
\hline cerebral injuries & inflicted cerebral injury & shearing injury \\
\hline cervical lumbar & inflicted traumatic brain injury & skull fractures \\
\hline cervical spine injury & inflicted traumatic head injury & spinal cord injury \\
\hline cervical spine & interhemispheric & subarachnoid hematoma \\
\hline neuropathology & intracerebral bleeding & subdural hematoma \\
\hline contusion & intracerebral haemorrhage & subdural haematoma \\
\hline contusional tear & intracerebral hemorrhage & subdural hygroma \\
\hline cranial injury & intracranial haemorrhage & thoracic lumbar sacral \\
\hline craniocerebral trauma & intracranial hemorrhage & traumatic effusions \\
\hline craniocervical & intracranial injuries & ventricular haemorrhage \\
\hline diagnostic triad & intraparenchymal tear & ventricular hemorrhage \\
\hline diffuse axonal injury & intraparenchymal haemorrhage & whiplash impact syndrome \\
\hline eggshell fracture & intraparenchymal hemorrhage & whiplash injury \\
\hline encephalomalacia & & whiplash shaken infant \\
\hline \multicolumn{3}{|l|}{ encephalopathy } \\
\hline \multicolumn{3}{|l|}{ extracranial CNS injury } \\
\hline \multicolumn{3}{|l|}{ extradural haemorrhage } \\
\hline extradural hemorrhage & & \\
\hline
\end{tabular}

extradural hemorrhage

\begin{tabular}{|c|c|}
\hline \multicolumn{2}{|l|}{ Search strategy } \\
\hline 1. Child/ & 54. (retinal hemorrhage or retinal haemorrhage).af. \\
\hline 2. (child: or infant: or toddler:).af. & 55. skull fracture:.af. \\
\hline 3. 1 or 2 & 56. (spinal cord injury adj3 radiologic abnormality).af. \\
\hline 4. non-accidental injur:.af. & 57. spinal cord injur:.af. \\
\hline 5. non-accidental trauma.af. & 58. (subdural haematoma or hemotoma).af. \\
\hline 6. (non-accidental: and injur:).af. & 59. (subarachnoid hematoma or subarachnoid haematoma).af. \\
\hline 7. soft tissue injur:.af. & 60. (subdural haemorrhage or subdural hemorrhage).af. \\
\hline 8. physical abuse.af. & 61. (ventricular haemorrhage or ventricular hemorrhage).af. \\
\hline 9. (inflicted brain injur: or inflicted cerebral injur:).af. & 62. whiplash impact syndrome.af. \\
\hline $\begin{array}{l}\text { 10. (inflicted traumatic head injur: or inflicted traumatic brain } \\
\text { injur:).af. }\end{array}$ & 63. whiplash injur:.af. \\
\hline 11. (or/4-10) and 3 & 64. whiplash shaken infant.af. \\
\hline 12. (child abuse or child maltreatment or child protection).af. & 65. infarction.af. \\
\hline 13. (battered child or shaken baby or battered baby).af. & 66. (hypoxic-ischemic injur: or hypoxic-ischaemic injur:).af. \\
\hline 14. (battered infant or shaken infant).af. & 67. (contusion: or contusional tear).af. \\
\hline 15. Shak: Baby Syndrome.af. & 68. (hematoma or haematoma).af. \\
\hline 16. shak: impact syndrome.af. & 69. laceration:.af. \\
\hline 17. Caffey-Kempe syndrome.af. & 70. shearing injur:.af. \\
\hline 18. battered child syndrome.af. & 71. traumatic effusion:.af. \\
\hline
\end{tabular}


Table 1 Continued

\begin{tabular}{|c|c|}
\hline \multicolumn{2}{|l|}{ Search strategy } \\
\hline 19. *“Child Abuse"/di [Diagnosis] & 72. subdural hygroma.af. \\
\hline 20. infant traumatic stress syndrome.af. & 73. hygroma.af. \\
\hline 21. parent-infant traumatic stress syndrome.af. & 74. interhemispheric.af. \\
\hline 22. or/12-21 & 75. parafalcine.af. \\
\hline 23. 11 or 22 & 76. (brain or brainstem).af. \\
\hline 24. abusive head trauma.af. & 77. cerebral.af. \\
\hline 25. bleeding into brain.af. & 78. intraparenchymal.af. \\
\hline 26. blow to the head.af. & 79. sciwora.mp. \\
\hline 27. brain damage.af. & 80. spinal cord injury without radiologic abnormality.af. \\
\hline 28. (brain haemorrhage: or brain hemorrhage:).af. & 81. cervical lumbar.af. \\
\hline 29. (brain swelling or cerebral edema).af. & 82. thoracic lumbar sacral.af. \\
\hline 30. cerebral injur:.af. & 83. leptomeningeal cyst.af. \\
\hline 31. cervical spine injur:.af. & 84. growing skull fracture.af. \\
\hline 32. cervical spine neuropathology.af. & 85. hydrocephalus.af. \\
\hline 33. cranial injur:.af. & 86. laminar necrosis.af. \\
\hline 34. craniocerebral trauma.af. & 87. encephalomalacia.af. \\
\hline 35. diffuse axonal injur:.af. & 88. cerebral atrophy.af. \\
\hline 36. extracranial CNS injur:.af. & 89. craniocervical.af. \\
\hline 37. extracranial Central Nervous System injur:.af. & 90. encephalopathy.af. \\
\hline 38. central nervous system injur:.af. & $\begin{array}{l}\text { 91. (intraparenchymal hemorrhag: or intraparenchymal } \\
\text { haemorrhag:).af. }\end{array}$ \\
\hline 39. (extradural haematoma or hematoma).af. & 92. Haemorrhagic retinopathy.af. \\
\hline 40. extradural haemorrhage.af. & 93. hemorrhagic retinopathy.af. \\
\hline 41. haemorrhagic retinopathy.af. & 94. (Haemorrhagic retinopathy adj3 retinal haemorrhages).af. \\
\hline 42. (head inur: or head trauma).af. & 95. Extradural haemorrhage.mp. or Extradural hemorrhage.af. \\
\hline 43. impact injur:.af. & 96. (extradural haemorrhag: or extradural hemorrhag:).af. \\
\hline 44. intracerebral bleeding.af. & $\begin{array}{l}\text { 97. (extradural spinal haemorrhag: or extradural spinal } \\
\text { hemorrhag:).af. }\end{array}$ \\
\hline 45. (intracerebral haemorrhage or intracerebral hemorrhage).af. & 98. (Haemorrhagic retinopathy adj3 retinal haemorrhag:).af. \\
\hline 46. (intracranial haemorrhage or intracranial hemorrhage).af. & 99. (Hemorrhagic retinopathy adj3 retinal hemorrhag:).af. \\
\hline 47. intracranial injur:.af. & 100. (retinal hemorrhag: or retinal haemorrhag:).af. \\
\hline $\begin{array}{l}\text { 48. (intraventricular hematoma or intraventricular } \\
\text { haematoma).af. }\end{array}$ & 101. or/24-100 \\
\hline 49. (multiple skull fractur: or eggshell fractur:).af. & 102. 23 and 101 \\
\hline 50. (neurological injur: adj3 child abuse).af & \\
\hline 51. neuropathology.af. & \\
\hline 52. non-accidental head injur:.af. & \\
\hline 53. (parenchymal contusion or laceration).af. & \\
\hline
\end{tabular}

extremely conservative imputation approach to account for this missing information. ${ }^{17}$ For example, if we are analysing a feature that we suspect may be associated with iBI, for instance, retinal haemorrhages: in the group of children with iBI, if only $6 / 10 \mathrm{iBI}$ children underwent fundoscopy, we made the assumption that the four children who were not examined would not have had the feature.

By contrast, in the group of children with niBI, if an investigation for this feature was not performed, for example, if only $2 / 10$ niBI children underwent fundoscopy, we made the assumption that the eight children who were not examined would have had the feature. Only in the case of skull fractures, a feature whose presence we suspect to be associated with niBI, was the opposite imputation performed. We believe that by approaching the missing data in this way, we err on the side of caution, and risk underestimating, rather than overestimating, the strength of the discrimination provided by this feature. We have specifically employed this technique to avoid reinforcing any prior assumptions, but rather to determine a valid estimate of the significance of each of the features under analysis.

These imputations being given, we then conducted a multilevel logistic regression analysis, ${ }^{18}$ allowing not only the prevalence of abuse to vary between studies, but also the odds ratios $(\mathrm{OR})$ for the features in question. By allowing the odds ratio to differ between studies, we again aim to minimise the risk of circularity, where an individual study may have overly relied upon a particular feature in order to arrive at the diagnosis of abuse. For each feature, we report the estimated odds ratio for the feature in discriminating between iBI and niBI, together with a $95 \%$ confidence interval $(95 \% \mathrm{CI})$. We also provide a $\mathrm{p}$ value to determine if this odds ratio is significantly different from 1, and a positive predictive value (PPV), the estimated probability of abuse given the presence of this feature in a child with brain injury, together with a $95 \%$ CI.

\section{RESULTS}

Of 320 reviewed studies, 14 met the inclusion criteria. ${ }^{14-16} 19-28$ All were published after 1995. Six were cross-sectional studies, ${ }^{19} 222427-29$ five case series, ${ }^{14} 16202325$ two case-control studies ${ }^{15}{ }^{26}$ and one a longitudinal cohort study. ${ }^{21}$ Eight studies involved prospective enrolment of cases. ${ }^{14} 16202325$ The six retrospective studies achieved full case ascertainment from hospital inpatient coding and/or radiology databases. Full study details are given in online appendix A.

Of the 306 studies excluded, the most common reasons for exclusion were the lack of comparative data or a rank of abuse of less than 1 or 2 . A small number (11 studies) were excluded 
Figure 1 Main phases and number of studies identified at each stage.

\section{* DATABASES SEARCHED 1970-2008}

All EBM Reviews, ASSIA, ChildData, CINAHL, EMBASE, MEDLINE, MEDLINE In-Process, SCOPUS, SIGLE, Social Care Online, TRIP Plus, ISI Proceedings, ISI Science Citation Index, ISI Social Science Citation Index

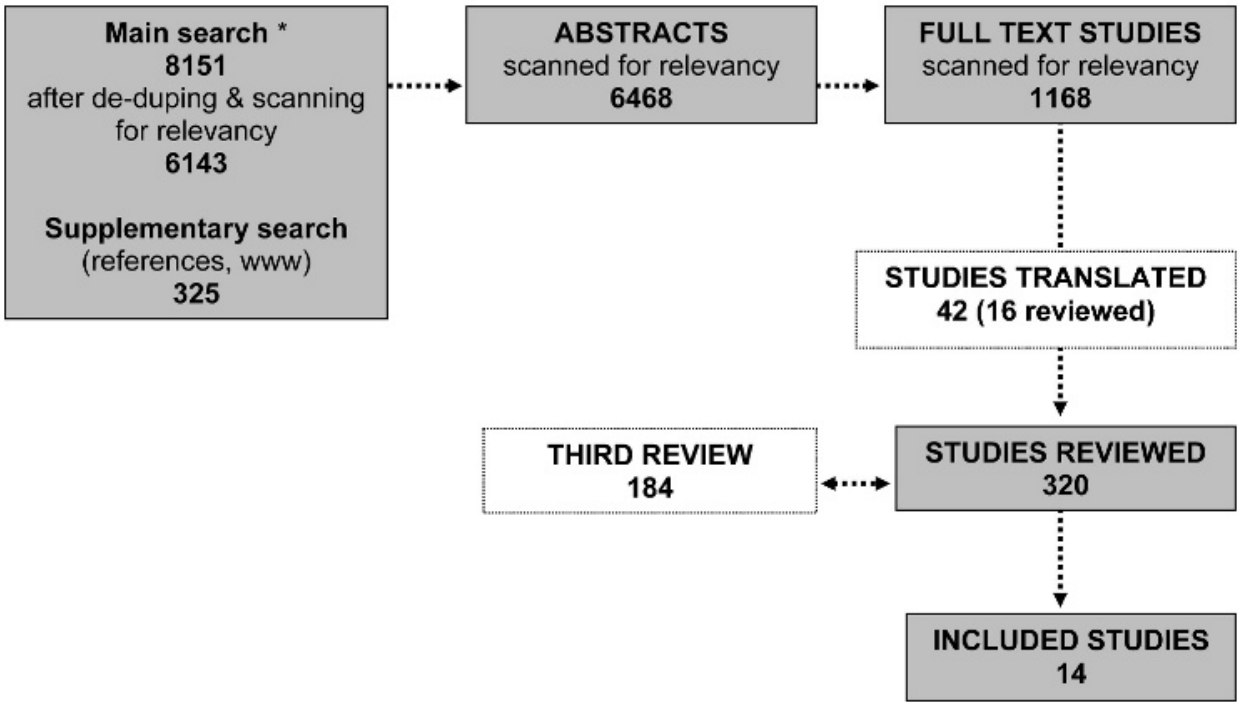

\section{Box 2 Inclusion and exclusion criteria}

\section{Inclusion criteria}

- children aged 0 to $<18$ years

- observational comparative study (cross-sectional/casecontrol/case series/longitudinal cohort)

- children with inflicted brain injury diagnosed on CT/MR: intracranial haemorrhage (extra-axial with or without additional brain injury - \pm intra-parenchymal haemorrhage, \pm diffuse axonal injury \pm hypoxic ischaemic injury \pm cerebral contusion \pm cerebral oedema)

- ranking of abuse 1 or 2 for inflicted brain injury (iBI)

- non-inflicted brain injury (niBI): non-inflicted aetiology confirmed

- children who were alive at presentation

- all language studies

- relevant clinical details given for each group

Exclusion criteria

- studies about complications, management or prognosis of iBI/ niBI

- consensus statements or personal practice studies

- non-comparative studies

- studies addressing exclusively post mortem neuropathological findings

- studies with mixed adult and child data, where the children's data cannot be extracted

- methodologically flawed studies (eg, significant bias, where iBI was not adequately confirmed or where inadequate clinical details were given)

- studies that only addressed head injury where there was no intracranial abnormality

- studies with a low surety of diagnosis of inflicted injury (rank 3-5 abuse) due to study design (expert opinion/review article, etc) and a further 10 included mixed adult and child data. Many studies were excluded on more than one basis (eg, rank of abuse/noncomparative/lack of detail on features for analysis).

Studies represented combined data on 1655 children, 779 of whom had suffered iBI and 876 niBI. Eleven of 14 studies included children less than 3 years of age. ${ }^{14-16} 1920222425$ 27-29 Seven studies ascertained all children who were hospitalised with traumatic head injuries, ${ }^{19-22} 252629$ six studies included all children with subdural haemorrhage of any aetiology (trauma, coagulopathy, metabolic disorder or post infection, etc $)^{14-16232528}$ and one study included children with subdural or extradural haemorrhage. ${ }^{27}$ The majority (seven) were conducted in the USA, ${ }^{19-22} 242627$ five were European ${ }^{14} 15232529$ (three UK ${ }^{14}{ }^{1523}$ ) and one each was from Australia $^{28}$ and Hong Kong. ${ }^{16}$ In nine studies, children were included solely on the basis of age and confirmation of cause. However, five had specific exclusion criteria (table 3).

Gender was recorded in 980 cases and was not a distinguishing feature. More boys than girls sustained brain injuries, regardless of aetiology (PPV of iBI if the child is a boy 0.397 (95\% CI 0.277 to 0.530 ), OR 0.697, p>0.2).

It was not possible to undertake a formal analysis of age as a discriminating feature as each study reported it differently. Eight studies confirmed that children with iBI were significantly younger than those who sustained niBI. ${ }^{1516202123242628}$ Of the

Table 2 Abuse ranking

\begin{tabular}{ll}
\hline Ranking & Criteria used to define abuse \\
\hline 1 & $\begin{array}{l}\text { Abuse confirmed at case conference or civil, family or criminal court } \\
\text { proceedings or admitted by the perpetrator, or independently witnessed }\end{array}$ \\
2 & $\begin{array}{l}\text { Abuse confirmed by stated criteria including multi-disciplinary assessment } \\
\text { Diagnosis of abuse defined by stated criteria }\end{array}$ \\
4 & $\begin{array}{l}\text { Abuse stated as occurring, but no supporting detail given as to how it was } \\
\text { determined }\end{array}$ \\
5 & $\begin{array}{l}\text { Abuse stated simply as "suspected", no details on whether it was } \\
\text { confirmed or not }\end{array}$
\end{tabular}


Table 3 Additional exclusion criteria of included studies

\begin{tabular}{ll}
\hline Author/year & Additional exclusion criteria \\
\hline Ewing-Cobbs L, Kramer L, Prasad M, et al $(1998)^{21}$ & $\begin{array}{l}\text { Prior traumatic brain injury, metabolic abnormality, preterm }(<32 \\
\text { weeks) } \\
\text { Coagulopathy, neonatal neurological abnormality, structural } \\
\text { abnormality, surgery or previous intracranial haemorrhage }\end{array}$ \\
Hettler J, Greenes DS $(2003)^{22}$ & $\begin{array}{l}\text { Subdural haemorrhage due to infection or surgery } \\
\text { Cardiopulmonary resuscitation, coagulation abnormality, severe } \\
\text { Fung ELW, Sung RYT, Nelson EAS, et al }(2002)^{16}\end{array}$ \\
Pierre-Kahn V, Roche 0, Dureau P, et al $(2003)^{25}$ & $\begin{array}{l}\text { Concussion, cerebral lacerations or contusions } \\
\text { Ettaro L, Berger RP, Songer T }(2004)^{20}\end{array}$ \\
\hline
\end{tabular}

Prior traumatic brain injury, metabolic abnormality, preterm $(<32$ abnormality, surgery or previous intracranial haemorrhage Subdural haemorrhage due to infection or surgery dehydration or delayed eye examination

Concussion, cerebral lacerations or contusions eight studies addressing children less than 3 years of age, where mean ages were available, ${ }^{15} 16192022242829$ three studies found no significant difference between $\mathrm{iBI}$ and niBI. ${ }^{19} 2229$ Five studies $^{15} 16202428$ stated that children with iBI were significantly younger than those with niBI. Four of these studies ${ }^{15} 162428$ gave the mean ages of children with iBI as less than or equal to 6 months, while the niBI groups ranged between 7.5 and 12.4 months. ${ }^{15} 162428$

\section{Combined feature analysis}

It was not possible to identify which children had specific combinations of features, as this level of detail was not given.

\section{Apnoea}

Apnoea appeared to be a highly discriminatory finding, with a PPV of $93 \%(97.5 \%$ CI 0.733 to 0.986$)$ and an OR of 17.062 (97.5\% CI 5.018 to 58.011, p<0.001). However, it was one of the least recorded clinical items, only being analysed by two authors (405 children), perhaps reflecting that its significance has only been recognised more recently. ${ }^{15} 30$

\section{Retinal haemorrhage}

Although 1283 children were included in studies that considered this feature, only 998 had fundoscopy (670 iBI and $328 \mathrm{niBI}$ ). Many children presenting with witnessed trauma did not have formal fundoscopy, whereas the majority of children with iBI did. Therefore, to account for studies where this was not explicit, ${ }^{20}{ }^{21}$ we used the conservative approach described above. Retinal haemorrhages were strongly associated with iBI, with a PPV of $71 \%(97.5 \%$ CI 0.483 to 0.868$)$ and an OR of 3.504 (97.5\% CI 1.088 to $11.280, p=0.03)$. A child with an intracranial injury who has co-existent retinal haemorrhages is significantly more likely to have iBI than niBI.

\section{Rib fractures}

Rib fractures were considered in studies representing 1002 children, and data were available on 903 children. Rib fractures were associated with inflicted injury, with a PPV of $73 \%$ (97.5\% CI 0.500 to 0.882$)$ and an OR of $3.027(97.5 \%$ CI 0.716 to 12.799$)$. The wide confidence interval reflects the fact that relatively few children had data recorded on this item. Our conservative analysis therefore results in lower significance.

\section{Seizures}

Seizures were considered in studies involving 760 cases, and results were documented in 758 . Seizures were more associated with iBI than niBI, but not significantly so, with a PPV of $66 \%$ (97.5\% CI 0.454 to 0.821$)$ and an OR of 2.924 (97.5\% CI 0.731 to 11.694, $\mathrm{p}=0.13)$.

\section{Long bone fractures}

One of the difficulties in analysing fractures as recorded in studies, is knowing whether the author is counting individual fractures, or individual children who have sustained fractures. In studies where this was not explicit, ${ }^{20}$ we made the assumption that the number of children with fractures was recorded, a conservative approach. Studies considering long bone fractures represent 1020 children, of whom 921 underwent skeletal imaging. Overall, the PPV of long bone fractures for iBI was $59 \%$ (97.5\% CI 0.48 to 0.69 ), OR $1.722(97.5 \%$ CI 0.824 to $3.601, p=0.14)$. Therefore a long bone fracture in association with an intracranial injury was a weak predictor for iBI, but not significantly so.

\section{Skull fractures and bruising to the head and neck}

Skull fractures were considered in studies representing 1014 children, and documented as present or absent in 916 children. Skull fractures were more strongly associated with niBI than iBI, with a PPV for iBI of $44 \%$ (97.5\% CI 0.223 to 0.678$)$, OR 0.852 (97.5\% CI 0.316 to $2.301, \mathrm{p}>0.2)$. Likewise, bruising to the head and neck was more common in the niBI children, but it was the least recorded item, weakening its significance. Only 212 cases had this feature considered, and overall the PPV of head and/or neck bruising for iBI was 37\% (97.5\% CI 0.035 to $0.906)$, OR $0.811(97.5 \%$ CI 0.070 to $9.410, p>0.2)$. No specific mention was made of the use of $3 \mathrm{D}$ reconstruction techniques to define such fractures; the authors simply recorded their presence or absence when looked for.

\section{DISCUSSION}

Making the clinical distinction between $\mathrm{iBI}$ and niBI in children is always going to be challenging. By producing a multilevel logistic regression of specific clinical features on over 1600 children, we have shown that there is scientific evidence to support the distinction between $\mathrm{iBI}$ and niBI, and we are able to offer positive predictive values and odds ratios for individual clinical indicators in children hospitalised with brain injury. The published literature does not allow an analysis of combined features.

This review is the largest of its kind, and offers for the first time a valid statistical probability of iBI when certain key features are present (eg, retinal haemorrhages). Although in some instances, for example, rib fractures, the sample size limits our statistical power to detect the full effect of this feature, as with any systematic review, we are of course limited by the amount of high quality data available in the published literature. However, even with this limited data set, the presence of rib fractures (PPV 73\%, OR 3.027) is still indicates an association with iBI rather than niBI, and emphasises how important it is to conduct appropriate imaging to determine if such fractures are present.

It appears that the younger the child, the greater the likelihood that an intracranial injury is due to abuse. 
However, children as old as 10 years with severe iBI have also been described in isolated case reports. ${ }^{31-34}$

Apnoea appears to be a critical distinguishing feature (PPV for abuse $93 \%$, OR 17.06, $\mathrm{p}<0.001$ ). There is increasing evidence that hypoxic ischaemic injury and its attendant complications are an integral part of the cascade in $\mathrm{iBI} .{ }^{4}$ The presence or absence of apnoea must be recorded in all cases of head injury in children.

Retinal haemorrhages are a valuable discriminator, reinforcing the need for fundoscopy on any child with unexplained intracranial injury, or suspected iBI. Indirect ophthalmoscopy should be conducted by an ophthalmologist, as studies have shown that other clinicians are either unable to conduct an accurate examination, or when they do, may miss up to $13 \%$ of retinal haemorrhages present. ${ }^{35}$

Fractures in physical abuse are often occult. ${ }^{36}{ }^{37}$ Therefore, in line with the Royal College of Paediatrics and Child Health/ Royal College of Radiologists standards for the radiological investigation of suspected physical abuse, any child aged less than 2 years in whom an inflicted injury is considered, should have a full skeletal survey, including oblique views of the ribs. ${ }^{38}$ Seizures were not a valuable discriminatory finding. Perhaps an analysis of specific patterns of seizures (eg, status epilepticus, complex, focal) would be more informative.

It was not possible to analyse the value of history given as a predictor, as a number of studies had used absence of a history of trauma or inconsistent explanation as part of their definition of abuse. ${ }^{20}{ }^{21}$ Only one large study set out to estimate the value of the initial history in predicting whether the head injury was inflicted or non-inflicted. ${ }^{22}$ Study design ensured that the history did not contribute to the decision as to whether the child belonged to the iBI or niBI group. The study concluded that having no history of trauma had a high specificity (0.97) and high PPV (0.92) for inflicted injury.

Although many studies addressed encephalopathic features, the differing classifications that were used (altered consciousness, coma, irritability, Glasgow Coma Score (GCS)) precluded any combined analysis of this information. It is recognised that performing a GCS on young infants is imprecise; a study ${ }^{24}$ that noted an increased relative risk of this item for iBI (RR 1.7, 95\% CI 0.9-3.2) did not attach weight to this feature.

We did not address social features which are more culturally specific, and less suited to meta-analysis. There is also the risk of introducing bias by undue reliance on social features, as shown by Jenny, ${ }^{3}$ who noted that white infants from two parent families were more likely to have their iBI missed than ethnic minority children or those living with one parent.

This review did not address biomechanical features. It is recognised that iBI can occur as a consequence of shaking, ${ }^{39} 40$ impact, ${ }^{41}$ shaking and impact, ${ }^{39}{ }^{42}$ water intoxication, ${ }^{43}{ }^{44}$ suffocation $^{45}$ or strangulation. ${ }^{46}$ In our review skull fracture and bruising to the head/neck were more strongly associated with niBI than iBI, suggesting blunt trauma as a common mechanism of niBI. Clinical evidence of impact may only be found on post mortem, ${ }^{42}$ so conclusions as to whether an impact injury has occurred or not in iBI cannot reliably be drawn from the clinical features alone.

It is recognised that subdural haemorrhage (SDH) can occur in infancy from other causes, and consideration must be given to possible organic disease, such as metabolic disorders (eg, glutaric aciduria), ${ }^{6}$ albeit this has characteristic MRI findings. While coagulopathy may cause intracerebral haemorrhage, ${ }^{7-9}$ it may also be secondary to an $\mathrm{BBI}^{47}$ highlighting the need for thorough investigations in this group. It is recognised that $\mathrm{SDH}$ in particular, may occur as a consequence of birth, particularly following instrumental delivery, ${ }^{48-50}$ although a neonatal SDH without skull fracture has also been described where the mother was assaulted ante-natally. ${ }^{51}$

While this review has highlighted certain clinical features that in association with intracranial injury have a high positive predictive value and odds ratio for $\mathrm{BI}$, such as retinal haemorrhage, apnoea or rib fractures, none of these features are exclusive to iBI. It is essential that the diagnosis of $\mathrm{iBI}$ is only made after taking into consideration full details on history (birth, medical, family, developmental, social, details of any reported trauma) and a detailed examination, and having actively excluded other relevant organic diseases. It is vital that future work should endeavour to collect data on all the features above, with detailed recording of precise abnormalities found, for example, on ophthalmology, if we are to refine these statistical correlations.

Baroness Kennedy has made it abundantly clear that clinicians must be able to cite scientific evidence to support their clinical opinions when providing evidence to the courts, ${ }^{52}$ and it is challenging for any clinician to keep up to date with all the current evidence (in the year 2007 alone 242 studies relating to $\mathrm{iBI}$ were published). Therefore, we feel that this unique, rigorously conducted systematic review will be a valuable resource for clinicians and other professionals in the field, providing, as it does, odds ratios of abuse for seven easily documented clinical features.

Acknowledgements: This work is based on reviews conducted by the Welsh Child Protection Systematic Review Group: T Abdelnour, M Barber, R Brooks, L Cole, M Gawne-Cain, C Graham, T Jaspan, N John, R Jones, K Kontos, A Mott, A Naughton, M Northey, L Price, I Prosser, S Rajaram, A Rawlinson, J Saunders, M Schmidt, J Sibert, D Slade, J deWaterNaude, J Venables, P Watts, S Datta, A Liu, N Stoodley.

Funding: Funding was provided by the National Society for the Prevention of Cruelty to Children (NSPCC), the Royal College of Paediatrics and Child Health (RCPCH) and the Welsh Assembly Government Research and Development Office (WORD).

Competing interests: None.

Provenance and peer review: Not commissioned; externally peer reviewed.

\section{REFERENCES}

1. Caffey J. The whiplash shaken infant syndrome: manual shaking by the extremities with whiplash-induced intracranial and intraocular bleedings, linked with residual permanent brain damage and mental retardation. Pediatrics 1974;54:396-403.

2. Coles L, Kemp A. Cues and clues to preventing shaken baby syndrome. Community Practitioner 2003;76:459-63.

3. Jenny C, Hymel KP, Ritzen A, et al. Analysis of missed cases of abusive head trauma. JAMA 1999;281:621-6.

4. Ichord RN, Naim M, Pollock AN, et al. Hypoxic-ischemic injury complicates inflicted and accidental traumatic brain injury in young children: the role of diffusion-weighted imaging. J Neurotrauma 2007;24:106-18.

5. Rubin DM, Christian CW, Bilaniuk LT, et al. Occult head injury in high-risk abused children. Pediatrics 2003;111(6 pt 1):1382-6.

6. Gago LC, Wegner RK, Capone A Jr, et al. Intraretinal hemorrhages and chronic subdural effusions: glutaric aciduria type 1 can be mistaken for shaken baby syndrome. Retina 2003;23:724-6.

7. Rutty GN, Smith CM, Malia RG. Late-form hemorrhagic disease of the newborn: a fatal case report with illustration of investigations that may assist in avoiding the mistaken diagnosis of child abuse. Am J Forensic Med Pathol 1999;20:48-51.

8. Strijks E, Poort SR, Renier WO, et al. Hereditary prothrombin deficiency presenting as intracranial haematoma in infancy [erratum appears in Neuropediatrics 2000;31:223]. Neuropediatrics 1999;30:320-4.

9. Vorstman EBA, Anslow P, Keeling DM, et al. Brain haemorrhage in five infants with coagulopathy. Arch Dis Child 2003;88:1119-21.

10. Barlow KM, Minns RA. Annual incidence of shaken impact syndrome in young children. Lancet 2000;356:1571-2.

11. Jayawant $\mathbf{S}$, Rawlinson $A$, Gibbon $F$, et al. Subdural haemorrhages in infants: population based study. BMJ 1998;317:1558-61.

12. NHS Centre for Reviews and Dissemination. Undertaking systematic reviews of research on effectiveness. CRD's guidance for those carrying out or commissioning reviews. CRD report no. 4, 2nd edn. York: University of York, 2001.

13. Maguire S, Moynihan S, Mann M, et al. A systematic review of the features that indicate intentional scalds in children. Burns 2008;34:1072-81.

14. Hobbs C, Childs AM, Wynne J, et al. Subdural haematoma and effusion in infancy: an epidemiological study. Arch Dis Child 2005;90:952-5. 
15. Kemp AM, Stoodley N, Cobley C, et al. Apnoea and brain swelling in non-accidental head injury. Arch Dis Child 2003;88:472-6.

16. Fung ELW, Sung RYT, Nelson EAS, et al. Unexplained subdural hematoma in young children: is it always child abuse? Pediatr Int 2002:44:37-42.

17. Van Belle G. Statistical rules of thumb. New York: Wiley-Interscience, 2002.

18. Matthews D, Farewell V. Using and understanding medical statistics. 4th edn. Basel: Karger, 2007

19. Bechtel K, Stoessel K, Leventhal JM, et al. Characteristics that distinguish accidental from abusive injury in hospitalized young children with head trauma. Pediatrics 2004;114:165-8.

20. Ettaro L, Berger RP, Songer T. Abusive head trauma in young children: characteristics and medical charges in a hospitalized population. Child Abuse Negl 2004;28:1099-111.

21. Ewing-Cobbs L, Kramer L, Prasad M, et al. Neuroimaging, physical, and developmental findings after inflicted and noninflicted traumatic brain injury in young children. Pediatrics 1998;102(2 Pt 1):300-7.

22. Hettler J, Greenes DS. Can the initial history predict whether a child with a head injury has been abused? Pediatrics 2003;111:602-7.

23. Hoskote A, Richards P, Anslow P, et al. Subdural haematoma and non-accidental head injury in children. Childs Nerv Syst 2002;18:311-17.

24. Keenan HT, Runyan DK, Marshall SW, et al. A population-based comparison of clinical and outcome characteristics of young children with serious inflicted and noninflicted traumatic brain injury. Pediatrics 2004;114:633-9.

25. Pierre-Kahn V, Roche 0, Dureau P, et al. Ophthalmologic findings in suspected child abuse victims with subdural hematomas. Ophthalmology 2003;110:1718-23.

26. Ruppel RA, Kochanek PM, Adelson PD, et al. Excitatory amino acid concentrations in ventricular cerebrospinal fluid after severe traumatic brain injury in infants and children: the role of child abuse. J Pediatr 2001;138:18-25.

27. Shugerman RP, Paez A, Grossman DC, et al. Epidural hemorrhage: is it abuse? Pediatrics 1996;97:664-48.

28. Tzioumi D, Oates RK. Subdural hematomas in children under 2 years. Accidental or inflicted? A 10-year experience. Child Abuse Negl 1998;22:1105-12.

29. Vinchon M, Defoort-Dhellemmes S, Desurmont M, et al. Accidental and nonaccidental head injuries in infants: a prospective study. J Neurosurg 2005:102(4 Suppl):380-4.

30. Geddes JF, Hackshaw AK, Vowles GH, et al. Neuropathology of inflicted head injury in children. I. Patterns of brain damage. Brain 2001;124(Pt 7):1290-8.

31. Conradi S, Brissie R. Battered child syndrome in a four year old with previous diagnosis of Reye's syndrome. Forensic Sci Int 1986;30:195-203.

32. Fisher SH. Skeletal manifestations of parent-induced trauma in infants and children. South Med J 1958;51:956-60.

33. Leikin SL, Guin GH. Clinical pathological conference: the battered child syndrome Clin Proc Child Hosp Dist Columbia 1963;19:301-6.

34. Mierisch RF, Frasier LD, Braddock SR, et al. Retinal hemorrhages in an 8-year-old child. An uncommon presentation of abusive injury. Pediatr Emerg Care 2004;20:118-20.
35. Morad Y, Kim YM, Mian M, et al. Nonophthalmologist accuracy in diagnosing retinal hemorrhages in the shaken baby syndrome. J Pediatr 2003;142:431-4.

36. Barsness KA, Cha ES, Bensard DD, et al. The positive predictive value of rib fractures as an indicator of nonaccidental trauma in children. J Trauma 2003; 54:1107-10

37. Merten DF, Radlowski MA, Leonidas JC. The abused child: a radiological reappraisal. Radiology 1983;146:377-81.

38. The Royal College of Radiologists and The Royal College of Paediatrics and Child Health. Standards for radiological investigations of suspected non-accidental injury. London: The Royal College of Paediatrics and Child Health, 2008. Available from http://www.rcr.ac.uk/docs/radiology/pdf/RCPCH_RCR_final.pdf (accessed 12 August 2009).

39. Biron D, Shelton D. Perpetrator accounts in infant abusive head trauma brought about by a shaking event. Child Abuse Negl 2005;29:1347-58

40. Schneider V, Woweries J, Grumme T. Trauma inflicted on a baby by shaking [Das 'Schuttel-Trauma' des Sauglings]. MMW Munch Med Wochensch 1979;121:171-6.

41. Lee ACW, Ou Y, Fong D. Depressed skull fractures: a pattern of abusive head injury in three older children. Child Abuse Negl 2003;27:1323-9.

42. Duhaime A-C, Gennarelli TA, Thibault LE, et al. The shaken baby syndrome. A clinical, pathological, and biomechanical study. J Neurosurg 1987;66:409-15.

43. Arieff Al, Kronlund BA. Fatal child abuse by forced water intoxication. Pediatrics 1999;103:1292-5.

44. Krugman SD, Zorc JJ, Walker AR. Hyponatremic seizures in infancy: association with retinal hemorrhages and physical child abuse? [see comment]. Pediatr Emerg Care 2000;16:432-4.

45. McIntosh BJ, Shanks DE, Whitworth JM. Child abuse by suffocation presenting as hypoxic-ischemic encephalopathy. Report of a patient. Clin Pediatr 1994;33:561-3.

46. Jain V, Ray M, Singhi S. Strangulation injury, a fatal form of child abuse. Indian J Pediatr 2001:68:571-2.

47. Graupman $\mathbf{P}$, Winston KR. Nonaccidental head trauma as a cause of childhood death. J Neurosurg 2006;104(4 Suppl):245-50.

48. Chamnanvanakij S, Rollins N, Perlman JM. Subdural hematoma in term infants. Pediatr Neurol 2002;26:301-4.

49. Looney CB, Smith JK, Merck LH, et al. Intracranial hemorrhage in asymptomatic neonates: prevalence on MR images and relationship to obstetric and neonatal risk factors. Radiology 2007;242:535-41.

50. Whitby EH, Griffiths PD, Rutter $S$, et al. Frequency and natural history of subdura haemorrhages in babies and relation to obstetric factors. Lancet 2004;363:846-51.

51. Stephens RP, Richardson AC, Lewin JS. Bilateral subdural hematomas in a newborn infant. Pediatrics 1997;99:619-21.

52. Kennedy H. Sudden unexpected death in infancy. A multi-agency protocol for care and investigation. London: The Royal College of Pathologists and The Royal College of Paediatrics and Child Health, September 2004. Available from http://www.rcpath.org/ index.asp?PagelD=455 (accessed 12 August 2009). 